\title{
The Link Between Decision Making Process and Performance: A Bibliometric Analysis
}

\author{
Ana Alexandra GORA'
}

\begin{abstract}
The concepts of decision-making process and performance are two subjects that are interconnected in the existing articles in the scientific literature. The purpose of this paper is to provide, using bibliometric techniques, a review of the evolution of existing research on the relationship between decision making process and performance concepts. In this respect, 1516 articles published between 2000 and 2018 and indexed in the Web of Science database were analyzed. The main results of this research are obtained from three types of analysis: an analysis of the 1516 selected papers, an analysis of the citations received from these articles and an analysis of the keywords. Thus, the most important findings illustrate how the number of papers related to the analyzed topic evolved in time, in which journals the most articles related to this topic appear, which are the authors and the institutions with the highest contributions on the topic. Also, the results highlight which are the most cited articles. Furthermore, the main results show a mapping and clustering of keywords that allow the analysis of the links between them, based on the information provided by the VOSviewer software. This research becomes useful to researchers and practitioners interested in the analyzed subject, helping to identify new research directions starting from an analysis of the scientific literature.
\end{abstract}

KEYWORDS: bibliometric analysis; co-occurrence; decision making process; keywords map; performance; VOSviewer.

JEL CLASSIFICATION: $C 88, M 21$

\section{INTRODUCTION}

This paper focuses on identifying the relationship between decision making process and performance, as two notions that are interconnected in the existing articles in the literature. The concept of decision-making process is a complex process that requires an overall analysis of the business environment and as well an analysis of the efficiency of a decision alongside with the consequences that it can have, consequences that influence the performance of an organization. Regarding this, it can be observed that the decision-making process is closely linked to the success of an organization and respectively to its performance, the decisionmaking strategies being determinant factors for the organizational performance.

Thus, the purpose of this article is to determine the existent connections between those two concepts, - decision making process and performance -, by studying from a scientifically point of view the articles published on this subject as well the most influential journals and authors on this area. The following sections of this paper present a review of the literature on the subject through the bibliometric techniques described in detail in the research methodology

\footnotetext{
${ }^{1}$ The Bucharest University of Economic Studies, Romania, anaalexandra.gora@gmail.com
} 
section. In this respect, there are analyzed 1516 articles published between 2000 and 2018 and indexed in the Web of Science (WoS) database. First, an analysis of the selected papers regarding the evolution in time of the papers is performed and their distribution by journals and countries. Also, the authors and institutions with contributions on the analyzed subject are presented. Then, an analysis of the citations received by the 1516 articles is performed to determine their impact in the scientific literature. Subsequently, a keywords map was created using VOS viewer software. After this, the conclusions and limitations of the research will be presented and suggestions for future research are included.

\section{LITERATURE REVIEW}

As Blanco-Mesa, Merigó and Gil-Lafuente (2017) claim, bibliometrics is a science that is based on the quantitative analysis of certain articles published in a specific domain. In this regard, it can be stated that the main objective of the bibliometrics is to evaluate the scientific literature in a specific area (Andrés, 2009). By using bibliometric indicators that allow the analysis of publications, citations and different sources of information that provide information on articles, journals, institutions, countries and authors from a investigated field, Moed (2009) considers that bibliometric analysis allows the evaluation of impact and influence in terms of the performance and quality of scientific publications. Moreover, Waltman, Van Eck and Noyons (2010) consider that, in bibliometric and scientometric research the attention is paid to the analysis of networks of documents, journals, authors or keywords, and the mapping and clustering techniques are most frequently used to study such networks.

Over time, various articles that use bibliometric analysis to investigate a specific research topic have appeared, using information provided by different databases with scientific articles and different data analysis software. Thus, Blanco-Mesa, Merigó and Gil-Lafuente (2017) carry out a bibliometric analysis on the subject of "fuzzy decision-making" to review the main contributions in this field. They use a wide range of bibliometric indicators and information provided by the Web of Science (WoS) database and in order to analyze and map the main trends in this area they use the VOSviewer software. In another study, Cicea et al. (2019) use bibliometric analysis to study the relationship between biomass and innovation, using information from the Scopus database. The authors evaluate 950 articles published in the period 1994-2018 on the subject analyzed and perform with the help of the bibliometric analysis the following analyzes: analysis of selected papers (distribution of papers by years, by countries, by journals, by areas, etc.), citation analysis and keyword analysis based on mapping and clustering of the keywords, using VOSviewer software (Cicea et al., 2019). Similarly, by using the bibliometric technique, Marinescu, Cicea and Colesca (2019) highlight the relationship between biofuels and innovation. In their study, these authors analyze 478 articles collected from the Scopus scientific papers database and underline the impact of the articles analyzed in time, identify the journals with publications related to the analyzed topic, and afterwards they develop a co-occurrence analysis of the keywords and make a keywords map with the help of VOSviewer software. Dabic, González-Loureiro and Harvey (2014) performed a bibliometric analysis to provide a review of the evolution of the expatriate research and their impact on the performance of a business. In this respect, 438 articles related to the expatriate subject were analyzed, more exactly articles published between 1970 and 2012 and extracted from the WoS database. Among the main information provided by this article, it can be highlighted that the presentation of the time evolution of articles related to the subject analyzed, the distribution of articles in journals and the presentation of the most cited authors with contributions in the area, as well as the most cited articles. Furthermore, a 
series of conceptual maps of keywords classified into 10 clusters are presented, made using Wordstat software.

Starting from studying other articles that use bibliometric analysis to determine the contributions existing in a certain field and on a certain research topic, this article attempts to highlight an overview of the connection between the notion of decision making process and performance and to highlight the trends on these subjects. The steps taken to carry out the bibliometric analysis proposed by this research are detailed in the following section.

\section{RESEARCH METHODOLOGY AND DATA COLLECTION}

The purpose of this research is to establish how the connection between the concept of "decision making process" and the notion of "performance" is reflected in scientific literature. Moreover, this paper aims to identify which are the other concepts with which the two notions interact and which connections are created between them, using as a method of analysis the bibliometric techniques. Regarding the data collection for the current research and selection of articles for bibliometric analysis, these were collected by a keywords search undertaken using the Social Sciences Citation Index (SSCI) database of the ISI - Web of Science (WoS) platform, provided by Clarivate Analytics. WoS database was chosen because of the quality of the information that they provide. The search was performed by the keywords "decision making process*" and 'performance', using the 'and' connector between them. The wildcard * * was used to extract all the possible combinations of the concept of decision making process (such as decision-making process, decision making processes, etc.). Also, the signs “" " were added to find records containing the exact phrase "decision making process". The two keywords were searched by the topic section of the WoS database (includes searches in the following fields within a record: title, abstract, author keywords and Keywords plus) and the search was limited to the period 2000 and 2018. According to these criteria, 1574 articles were obtained. Only articles written in English were chosen and this filtering process reduced the number of articles from 1574 to 1520 . As the document type limit, only the document type 'article' and review' were selected. Thus, it was obtained a final list containing a total of 1516 documents dealing with the terms of decision making process and performance in title, abstract or keywords from the period 2000 to 2018. Following the selection of papers and consulting the scientific literature (Blanco-Mesa, Merigó \& Gil-Lafuente, 2017; Cicea et al. 2019; Dabic, González-Loureiro \& Harvey, 2014; Marinescu et al. 2019), with the help of all 1516 documents selected it was pursued to carry out 3 types of analyzes:

1. Analysis of the selected papers (the papers distributions by years and countries, Top 16 most productive journals, top 11 institutions and authors with contributions related to the subject of decision making process - performance, paper distribution according to research areas);

2. Analysis of the number of citations received by the selected papers (presentation of the top of the most cited scientific papers);

3. Keywords` analysis (including occurrence, co-occurrence (link strength) and links between them and a keywords map).

In order to carry out these three types of analysis proposed by the present research, different research methods were used. Thus, regarding the first type of analysis, namely the analysis of the selected papers (number of papers written over time, distribution of papers in journals, number of papers by countries, top institutions and authors with contributions related to the subject of decision making process - performance), the information provided by the Web of Science database through the "Analyze Results" section was used. In order to perform the 
second type of analysis, namely the analysis on the number of citations received by the selected papers to determine the impact obtained from these articles, the information provided by the WoS platform in the section "Create Citation Report" was used. Also, a software tool developed by Nees Jan van Eck and Ludo Waltman (2011), called VOSviever (VOS) was used to perform the last type of analysis, namely for keywords` analysis and for a conceptual keywords` mapping. In the current research, VOSviewer software version 1.6.11 (Van Eck \& Waltman, 2019) was used for keywords` analysis. VOSviewer is a computer program that can be used for creating, visualizing and exploring bibliometric maps of science (Van Eck and Waltman, 2010). To build a visualization map of keyword, the software VOSviewer uses the VOS (visualization of similarities) mapping technique (Van Eck \& Waltman, 2007).

\section{DATA ANALYSIS AND DISCUSSION}

Considering those three types of analysis that are intended to be performed through this paper, within this section are presented the data analysis and the results obtained.

\subsection{Analysis of the $\mathbf{1 5 1 6}$ selected papers}

The evolution in time of the 1516 selected articles related to the topic of decision making process and performance, published between 2000 and 2018 is presented in Figure 1. Analyzing the information provided by Figure 1 it can be observed that in the period 20002018, in general, the number of scientific papers related to the analyzed subject it has increased. Thus, during the whole period analyzed the number of articles published from one year to another has increased, except 2005, 2010 and 2017, in which there were slight decreases. In addition, in the period 2000-2018, the average number of articles published on each year was 80 . The maximum number of articles, namely $228(15.04 \%)$ were published in 2018 and the smallest number of articles published in a year, more exactly $14(0.92 \%)$ was registered in 2000 .

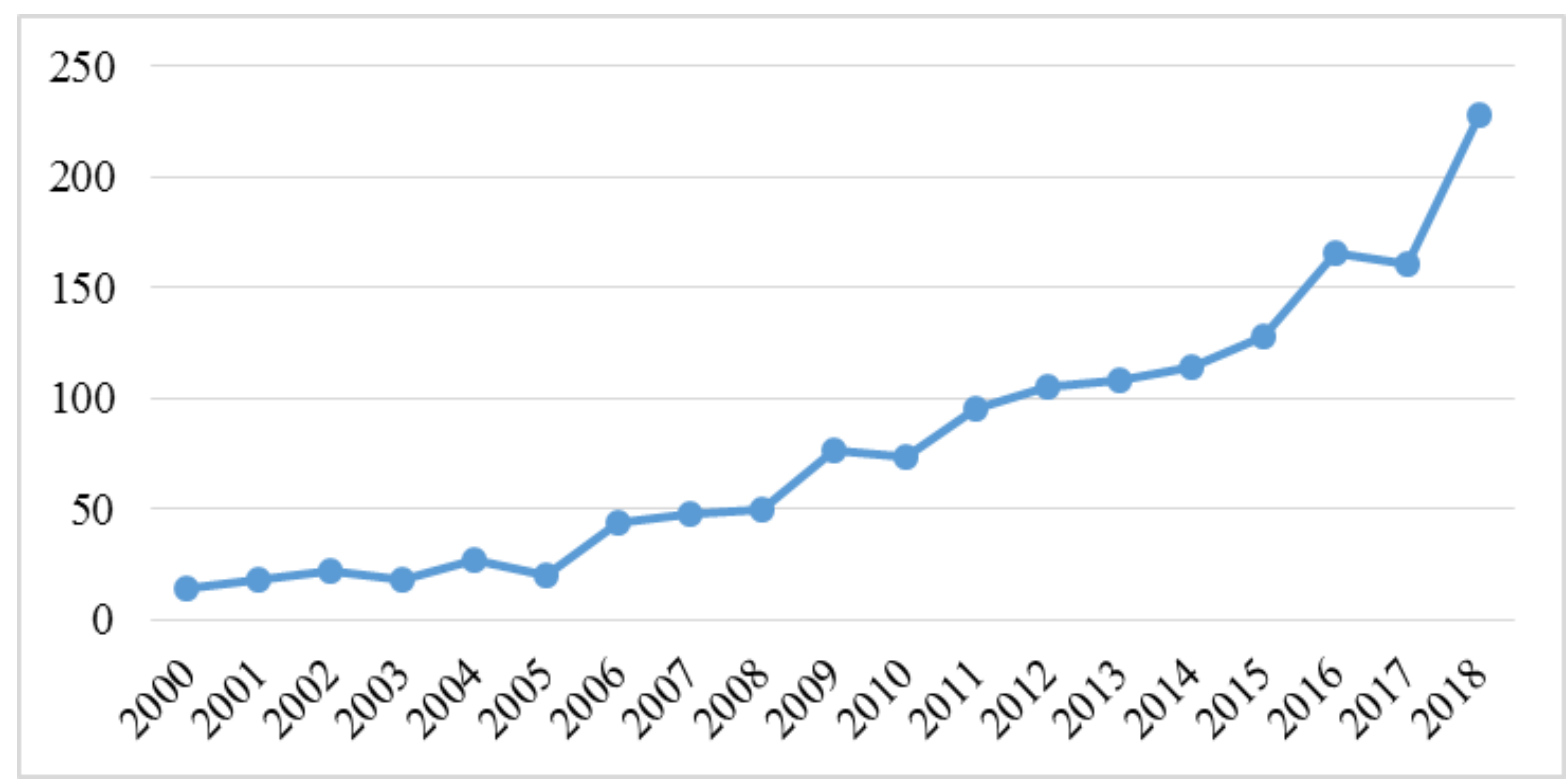

Figure 1. Published papers per year Source: WoS (2019a)

Moreover, it can be observed that only in the last 5 years of the analyzed period, respectively between 2014 and 2018 there were published more than half of the total of the 1516 analyzed articles, respectively $52.75 \%$, the rest of the articles being distributed in the period 2000-2013. 
Considering the distribution of the papers, according to the country to which the authors or co-authors are affiliated, there are 90 countries with this feature in all the selected papers. The top 15 countries to which at least one of the authors of the selected papers is affiliated is presented in Table 1.

Table 1. Distribution of papers by country to which the authors are affiliated (Top 15)

\begin{tabular}{|c|c|c|c|}
\hline Rank & Countries/Regions & Number of articles & Percentage of 1516 \\
\hline 1 & USA & 468 & $30.87 \%$ \\
\hline 2 & England & 183 & $12.07 \%$ \\
\hline 3 & Peoples R China & 117 & $7.72 \%$ \\
\hline 4 & Australia & 94 & $6.20 \%$ \\
\hline 5 & Canada & 94 & $6.20 \%$ \\
\hline 6 & Spain & 94 & $6.20 \%$ \\
\hline 7 & Italy & 81 & $5.34 \%$ \\
\hline 8 & Netherlands & 77 & $5.08 \%$ \\
\hline 9 & Germany & 76 & $5.01 \%$ \\
\hline 10 & Taiwan & 53 & $3.50 \%$ \\
\hline 11 & South Korea & 42 & $2.77 \%$ \\
\hline 12 & France & 40 & $2.64 \%$ \\
\hline 13 & Brazil & 37 & $2.44 \%$ \\
\hline 14 & Belgium & 36 & $2.37 \%$ \\
\hline 15 & Switzerland & 33 & $2.18 \%$ \\
\hline & & & \\
\hline & & Source $(2019 \mathrm{a})$ & \\
\hline
\end{tabular}

As can be noticed from Table 1, three countries accumulate more than half $(50.66 \%)$ of the total number of articles distributed according to the country to which the authors are affiliated, namely the USA, England, and Peoples R. China. Thus, the country with the largest number of articles to which at least one author of the selected papers is affiliated is the United State of America with a total of 468 documents (30.87\%), followed by England with 183 (12.07\%) articles. Moreover, it can be observed that in the Top 15 of the breakdown of the papers by authors' country there are 8 countries in Europe with a total of 620 articles $(40.90 \%$ of the total of the 1516 documents selected). Regarding the situation of Romania, there are 10 articles out of the total of 1516 which have at least one author affiliated with this country.

Table 2 presents the main journals that have published scientific articles related to the topic of decision making process - performance, in 2000-2018 period.

In total, the 1516 selected articles were published in 790 journals with concerns related to the subject analyzed through this research.

Analyzing Table 2, it can be observed that in the rank list of Top 16 Journals according to the number of documents published in each journal, there are 242 documents out of the total of 1516 papers published in the period 2000-2018, which represent $15.96 \%$ of the 1516 selected articles. The largest number of articles published in a journal was 33 in the Journal of Cleaner Production, cumulating $2.18 \%$ of the total number of 1516 articles. 
Table 2. Top 16 most productive Journals

\begin{tabular}{|c|l|c|}
\hline Rank & \multicolumn{1}{|c|}{ Journal } & Documents \\
\hline 1 & Journal of Cleaner Production & 33 \\
\hline 2 & Management Decision & 24 \\
\hline 3 & Sustainability & 21 \\
\hline 4 & International Journal of Production Economics & 19 \\
\hline 5 & European Journal of Operational Research & 17 \\
\hline 6 & Plos One & 17 \\
\hline 7 & Expert Systems with Applications & 15 \\
\hline 8 & Omega International Journal of Management Science & 13 \\
\hline 9 & Journal of Business Ethics & 12 \\
\hline 10 & Decision Support Systems & 11 \\
\hline 11 & International Journal of Production Research & 11 \\
\hline 12 & Journal of Product Innovation Management & 11 \\
\hline 13 & Business Process Management Journal & 10 \\
\hline 14 & Energy Policy & 10 \\
\hline 15 & Frontiers in Psychology & 9 \\
\hline 16 & Group Decision and Negotiation & 9 \\
\hline
\end{tabular}

Source: $\operatorname{WoS}(2019 \mathrm{a})$

Top authors and institutions with contributions related to the topic of decision making process and performance are presented in Table 3.

Table 3. Top 11 authors and institutions with contributions in the studied field

\begin{tabular}{|c|c|c|c|c|}
\hline \multicolumn{2}{|c|}{ Authors } & \multirow{2}{*}{ Rank } & \multicolumn{2}{c|}{ Institutions } \\
\cline { 4 - 5 } \cline { 4 - 5 } Authors name & Contributions & & Contributions & Institutions name \\
\hline Brand M & 6 & 1 & 28 & University of London \\
\hline Elbanna S & 6 & 2 & 27 & University of California System \\
\hline Park J & 6 & 3 & 26 & University of Texas System \\
\hline Ferreira Faf & 5 & 4 & 21 & University of North Carolina \\
\hline Bechara A & 4 & 5 & 19 & State University System of Florida \\
\hline Bonner B1 & 4 & 6 & 18 & Vrije Universiteit Amsterdam \\
\hline Busemeyer Jr & 4 & 7 & 17 & Erasmus University Rotterdam \\
\hline Carmeli A & 4 & 8 & 17 & Pennsylvania Commonwealth System \\
of Higher Education Pcshe
\end{tabular}

Source: WoS (2019a)

A total of 4,468 authors contributed to the writing and publication of the 1516 selected articles. From Table 3 it can be observed who the authors are with the most scientific papers written on the topic of decision making process - performance. In this regard, it can be 
established that the highest number of individual contributions related to the analyzed topic is 6 articles and 3 authors are in the top according to this criteria: Brand M., Elbanna S. and Park J. Regarding the affiliation of the 3 authors of the Top 11, none of them is affiliated with any of the institutions presented in Table 3.

The top of institutions according to the number of articles whose authors or co-authors are affiliated with the respective institutions is presented in Table 3. From this table, it can be seen that the largest number of articles affiliated with an institution is 28 , at the University of London. On the 2 nd and 3rd place among the institutions with the most affiliated documents are the University of California System and the University of Texas System with 27 and respectively 26 articles. Moreover, analyzing the rank list of Top 11 institutions based on the number of documents in which the authors or co-authors are affiliated, it can be observed that $63.64 \%$ of the institutions are from the USA and the remaining $36.36 \%$ are institutions from Europe.

Table 4 reflects the Top 10 research areas according to the number of articles published and associated with this area, an article can be classified in several research areas at the same time.

Table 4. Top 10 research areas on basis of the number of published articles

\begin{tabular}{|c|l|c|}
\hline Rank & \multicolumn{1}{|c|}{ Research areas } & Documents \\
\hline 1 & Business Economics & 542 \\
\hline 2 & Engineering & 243 \\
\hline 3 & Psychology & 206 \\
\hline 4 & Environmental Sciences Ecology & 152 \\
\hline 5 & Computer Science & 149 \\
\hline 6 & Operations Research Management Science & 128 \\
\hline 7 & Science Technology Other Topics & 92 \\
\hline 8 & Social Sciences Other Topics & 91 \\
\hline 9 & Neurosciences Neurology & 84 \\
\hline 10 & Health Care Sciences Services \\
\hline
\end{tabular}

Source: $\operatorname{WoS}(2019 a)$

Moving on to the information provided by Table 4, it can be seen that most articles related to the subject of decision making process and performance, namely 542, are classified as part of the "Business Economics" research area. On the second place is the domain "Engineering" according to the number of articles associated with a research area, with 243 documents and the third place is occupied by "Psychology" with a total of 206 scientific articles.

\subsection{Citations`analysis}

The second analysis performed through this research is the analysis of the number of citations received by the 1516 selected papers in order to determine the impact of these papers during the analyzed period. In this regard, Table 5 presents the Top 10 most cited scientific papers related to the topic of the decision making process - performance, published in the period 2000-2018. 
Table 5. Top 10 most cited articles during 2000-2018

\begin{tabular}{|c|l|c|c|}
\hline Rank & \multicolumn{1}{|c|}{ Authors } & \multicolumn{1}{|c|}{$\begin{array}{c}\text { Total citations } \\
\mathbf{2 0 0 0 - 2 0 1 8}\end{array}$} & $\begin{array}{c}\text { Average citations } \\
\text { per year }\end{array}$ \\
\hline 1 & Bagstad, Semmens, Waage et al. (2013) & 11849 & 1974.83 \\
\hline 2 & Manes, Sahakian, Clark, et al. (2002) & 535 & 31.47 \\
\hline 3 & Bechara (2004) & 520 & 34.67 \\
\hline 4 & Handfield, Walton, Sroufe, et al. (2002) & 445 & 26.18 \\
\hline 5 & Carpenter \& Westphal (2001) & 395 & 21.94 \\
\hline 6 & Certo (2003) & 329 & 20.56 \\
\hline 7 & Xiao \& Benbasat (2007) & 290 & 24.17 \\
\hline 8 & Webb (2001) & 281 & 15.61 \\
\hline 9 & Reid \& De Brentani (2004) & 281 & 18.73 \\
\hline 10 & Lyon, Lumpkin \& Dess (2000) & 274 & 14.42 \\
\hline
\end{tabular}

Source: WoS (2019b)

Based on the information provided by the "Create Citation Report" section of the WoS database (WoS, 2019b) it can be stated that the 1516 articles selected for analysis received a total number of 39533 citations in the period 2000-2018. Currently, at the time of the analysis (23 October 2019), these articles accumulate a total of 44836 citations, which indicates an increase of $5303(13.41 \%)$ in the number of citations compared to the analyzed period (2000-2018). Considering the Top 10 of the most cited articles, Table 5 shows the total number of citations accumulated by each article from the time of publication until the end of 2018. Thus, it can be noticed that the highest number of citations received by an article is 11,849 citations, belonging to the authors Bagstad, Semmens, Waage et al. (2013), which means that this article received an average of 1974.83 citations per year. In this sense, this article holds $29.97 \%$ of the total number of citations received by the 1516 articles in the analyzed period. Moreover, based on the information provided by Table 5, it can be concluded that the article in the first place on the Top 10 most cited articles is also the most recent article, published in 2013. Also, by analyzing the top authors with contributions related to the topic analyzed, as Table 3 shows, it can be observed that the authors of the most cited article are not in that top, which means that they have published under 15 articles related to the topic of decision making process-performance.

The following two articles in the Top 10 most cited articles are the articles of the authors Manes, Sahakian, Clark, et al. (2002) and Bechara (2004), that received from the moment of their appearance until the end of 2018 a total of 535 and respectively 520 citations. By correlating the information offered by Table 5 with the information provided by Table 3, it can be stated that only Bechara, the author of the article in position 3 according to the number of citations accumulated, is also in the Top 11 authors with contributions related to the analyzed subject, contributing with a total number of 4 articles.

Regarding the journals in which the articles with the highest number of citations received were published, it can be observed that only the article in position 9 of Table 5 (Reid \& De Brentani, 2004) is published in a journal that is in the Top 16 journals that have published scientific articles related to the topic of decision making process - performance, in 2000-2018 period, namely in the Journal of Product Innovation Management, as shown in Table 2. 


\subsection{Keywords`analysis}

The last category of analysis that was performed through this research refers to an analysis of the keywords within the 1516 articles analyzed. In order to carry out this analysis, both the keywords provided by the authors and the "keywords plus" for each article were used. As explained in another bibliometric analysis study (Dabic, González-Loureiro \& Harvey, 2014), the WoS database automatically extracts from the titles of the documents a series of "keywords plus" which represent the best words the system identifies as matching the main theme the paper deals with.

To perform these keywords` analysis and to create a conceptual keywords visualization map based on bibliographic data, VOSviewer software was used (Van Eck \& Waltman, 2019). Preliminary to this analysis was created a database with a series of information regarding the 1516 selected articles, information provided by the WoS database. Thus, information regarding the authors' name, article title, abstract, year of publication, and keywords mentioned in each article were extracted.

Subsequently, the information obtained from the WoS platform was entered into the software VOSviewer (Van Eck \& Waltman, 2019), which allowed a co-occurrence analysis of the keywords contained in each article.

Once the database with information on the 1516 articles was introduced in VOSviewer software (Van Eck \& Waltman, 2019), it counted a total of 8032 keywords reported in all articles analyzed, articles related to the topic of decision making process and performance. Given the large number of keywords cumulated by all 1516 articles, a minimum number of the occurrence per keywords equal to 30 was chosen for analysis (where occurrence means the number of documents in which a keyword occurs) and thus were retained for analysis 38 keywords. Based on the minimum number of 30 occurrences per keywords, and more precisely based on the selection of only those keywords that are mentioned in at least 30 articles, for all those 38 keywords kept for analysis, the total strength of the links with other keywords (co-occurrence) was calculated. Thus, Table 6 highlights the 38 keywords, along with their occurrence, the links between them and the co-occurrence (or the total strength between them), sorted by their occurrence.

Analyzing Table 6 it can be seen that there are several keywords that appear written in various forms but they refer to the same concept, and their grouping would better highlight their occurrences or the number of articles in which that word is mentioned as a keyword. In this sense, a first grouping should be made between the words "decision-making" and "decision making", which shows that in total these words are found in 291 articles. The second grouping should be made between the concepts "performance", "firm performance" and "financial performance", which cumulates a total occurrence of 637. The third grouping is between the words "model" and "models" (205 total occurrences), the fourth grouping was between "system" and "systems" (107 total occurrences) and the last grouping was made between the words "strategy" and "strategies" (93 occurrences).

Considering the grouping presented above, it can be observed that regarding the analysis of the keywords, out of the total of 1516 selected articles, the keyword "performance" was found as the keyword in 637 documents, which means a percentage of $42.02 \%$ of the total number of papers selected. Concerning the phrase "decision making process" it is noted that it is not written in this form in the list of keywords but this term has the same meaning as the terms "decision making" and "decision-making". In this sense, it is observed that this concept of "decision making process" is found as a total keyword in 291 articles $(19.20 \%$ of the total of 1516 articles). Regarding the appearance of those two concepts in the rest of the documents, it 
turns out that they were found in the other documents in the title and abstract section, without being part of the keyword list.

Table 6. The keywords` occurrences, co-occurrences and links

\begin{tabular}{|c|c|c|c|c|}
\hline No.crt & Keyword & Occurrences & Links & Co-occurrences \\
\hline 1 & performance & 531 & 37 & 905 \\
\hline 2 & management & 190 & 36 & 421 \\
\hline 3 & decision-making & 173 & 36 & 261 \\
\hline 4 & model & 162 & 36 & 301 \\
\hline 5 & decision making & 118 & 34 & 231 \\
\hline 6 & information & 88 & 35 & 208 \\
\hline 7 & behavior & 86 & 33 & 176 \\
\hline 8 & framework & 78 & 34 & 187 \\
\hline 9 & impact & 77 & 33 & 157 \\
\hline 10 & systems & 67 & 32 & 135 \\
\hline 11 & firm performance & 65 & 28 & 89 \\
\hline 12 & perspective & 59 & 34 & 146 \\
\hline 13 & knowledge & 58 & 28 & 104 \\
\hline 14 & design & 54 & 33 & 129 \\
\hline 15 & innovation & 53 & 31 & 128 \\
\hline 16 & strategy & 52 & 32 & 128 \\
\hline 17 & risk & 52 & 32 & 111 \\
\hline 18 & industry & 51 & 33 & 132 \\
\hline 19 & uncertainty & 49 & 30 & 128 \\
\hline 20 & organizations & 45 & 31 & 111 \\
\hline 21 & determinants & 45 & 31 & 106 \\
\hline 22 & choice & 45 & 24 & 80 \\
\hline 23 & selection & 44 & 30 & 100 \\
\hline 24 & models & 43 & 29 & 86 \\
\hline 25 & prefrontal cortex & 43 & 11 & 63 \\
\hline 26 & strategies & 41 & 29 & 90 \\
\hline 27 & financial performance & 41 & 29 & 77 \\
\hline 28 & system & 40 & 26 & 82 \\
\hline 29 & sustainability & 39 & 28 & 83 \\
\hline 30 & analytic hierarchy process & 37 & 24 & 75 \\
\hline 31 & technology & 37 & 28 & 74 \\
\hline 32 & efficiency & 37 & 24 & 63 \\
\hline 33 & quality & 35 & 24 & 73 \\
\hline 34 & supply chain management & 34 & 30 & 91 \\
\hline 35 & governance & 33 & 25 & 70 \\
\hline 36 & satisfaction & 33 & 21 & 62 \\
\hline 37 & trust & 31 & 22 & 60 \\
\hline 38 & criteria & 30 & 23 & 66 \\
\hline
\end{tabular}

Source: Created by authors with VOSviewer (Van Eck \& Waltman, 2019) 
To move on to the mapping of the keywords and to group them in clusters, the technique of VOS clustering was used, a technique described in detail by the authors Waltman, Van Eck and Noyons (2010). Regarding the VOS clustering technique, as explained by other researchers in various studies (Cicea et al. 2019; Marinescu et al. 2019; Waltman, Van Eck \& Noyons, 2010), it uses the number of nodes, the links between them, the total number of links and the total strength between them (the co-occurrence). Specifically, starting from these elements, for each node is calculated the distance from other nodes, and each node is positioned in a two-dimensional space (a representation called mapping). In the end, the positive integer number obtained after positioning a node represents the cluster that the node belongs to. Starting from the explanations provided above, Figure 2 shows the visualization map of the 38 keywords presented in Table 6.

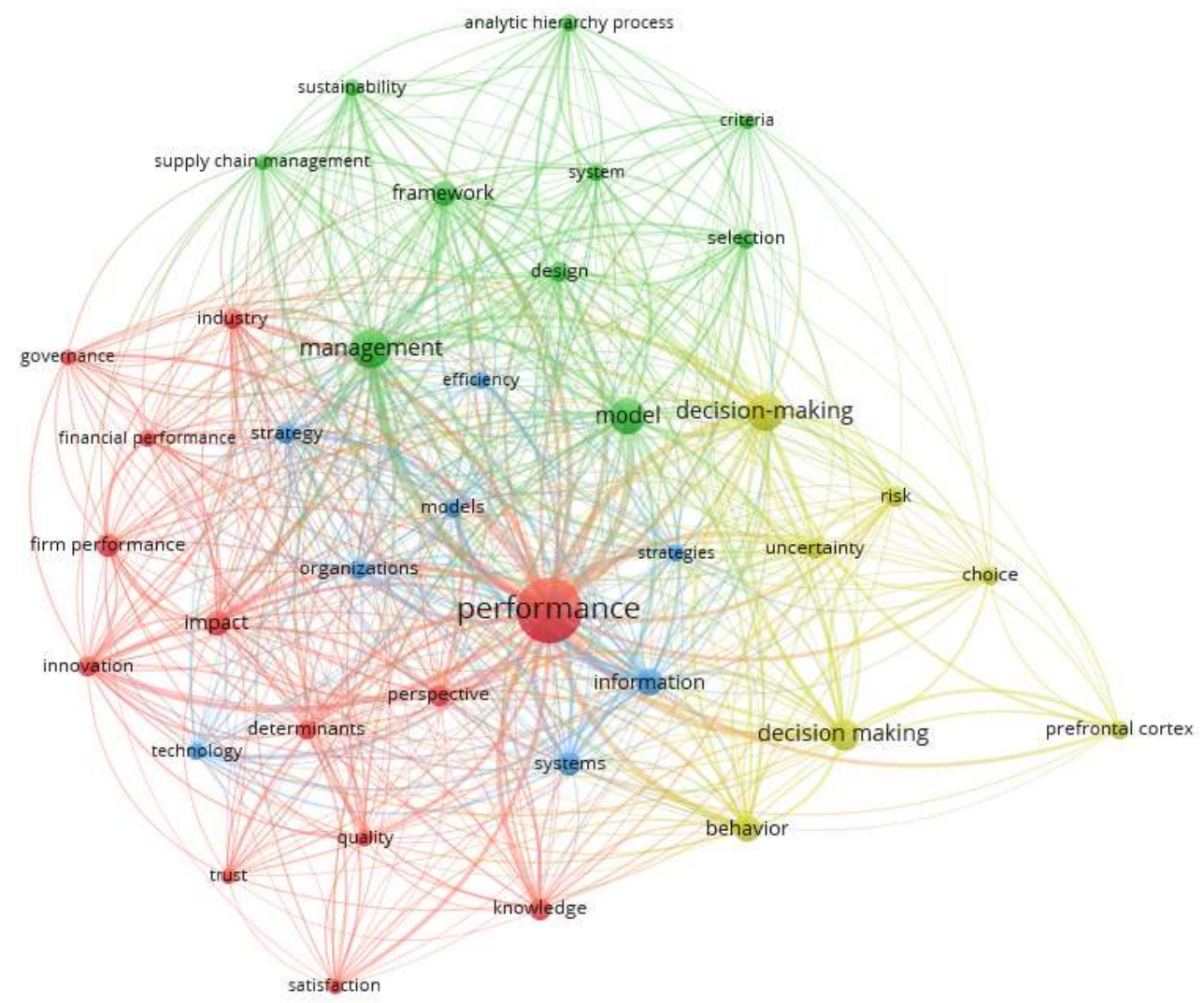

Figure 2. Keywords` map

Source: Created by authors with VOSviewer (Van Eck \& Waltman, 2019)

Analyzing Figure 2 it can be observed that it comprises 38 nodes (depending on the number of keywords that appear in at least 30 articles from the selected list, presented also in Table 6). A node means a keyword represented on the map and the size of a node is given by the number of keywords occurrences or by the number of articles in which those keywords are found. Both from Figure 2 and based on the information presented in Table 6 regarding the number of occurrences, it can be concluded which are the words found in most documents as keywords. In this article, it can be noted that the biggest node is that of the keyword "performance".

Regarding the grouping of the 38 keywords in clusters, it can be seen from Figure 2 that there are 4 clusters highlighted by different colors. The information provided by Figure 2 illustrates that in the red cluster there are the largest number of nodes, namely 13 , followed by the green 
cluster with 10 nodes, the blue one with 8 nodes and the smallest number of nodes in a cluster is 7 and can be found in the yellow cluster.

Concerning the links between the nodes, it can be emphasized that they are represented on the keywords map in the form of curved lines of different thickness. Thus, the thicknesses of a line is given by the link strength (or co-occurrence) that exists between those words. Furthermore, the distance between two nodes also indicates the relationship between the two words based on co-occurrence links. So this shows that the closer the two words are to each other, the stronger is the relatedness between them.

Based on the information in Figure 2 it can be observed that the strongest co-occurrences links between keywords exist between the words "performance" and "management" followed by the link between "performance" and "decision-making". However, if it would accumulate the existing links between the word "performance" and "decision-making" respectively "decision making", which refers to the same concept, it can be observed that the strongest cooccurrence link is formed between these 2 concepts. Regarding the connection of those two concepts analyzed with other concepts, it can be observed that they create strong links with the following words: "performance" - "model", "performance" - "innovation", "decisionmaking" - "model", "decision-making"- "management".

\section{CONCLUSIONS}

Through this article, by using bibliometrics techniques, the research trends on the subject of decision making process - performance were evaluated and highlighted. As can be identified from the research methodology section, 1516 papers related to the analyzed topic were analyzed, papers published between 2000 and 2018 and extracted from the Wob of Science database. At the base of this research stand three types of analyzes, carried out using various tools, as presented below.

The first analysis referred to an analysis of the 1516 selected papers, using information provided by the "Analyze Results" section of the WoS database (WoS, 2019a). The main results from this analysis show that during the period analyzed, the number of scientific articles related to the topic of decision making process-performance increased. Regarding the distribution of papers by country in which the authors are affiliated, the results show that 468 articles $(30.87 \%)$ have at least one author affiliated with the USA. Moreover, the journal with the highest number of articles published on the analyzed subject is Journal of Cleaner Production, in which are published 33 articles out of a total of 1516. The authors with the most individual contributions, namely 6 articles, are Brand M., Elbanna S. and Park J. and the largest number of documents affiliated with a single institution is 28 , at the University of London.

The second analysis was an analysis of the number of citations received by the 1516 articles. The main findings illustrate that in total the analyzed articles accumulate 39533 citations in the period 2000-2018 (WoS, 2019b). The most cited article belongs to the authors Bagstad, Semmens, Waage et al. (2013) and it is the most recent article in the top 10 most cited articles, cumulating $29.97 \%$ of the total number of citations received by the 1516 articles and received an average of 1974.83 citations per year. In addition, the results show that only one author of the articles in the Top 10 most cited articles is also in the top of the authors with contributions related to the topic analyzed, namely Bechara. By correlating the top of the most cited articles with the top of the journals that published articles related to the subject analyzed, 
only one article (Reid \& De Brentani, 2004) was published in such a journal, in the Journal of Product Innovation Management.

The last type of analysis referred to an analysis of the keywords (both the keywords declared by the authors in each article and the keywords plus) identified in the 1516 articles analyzed. Starting from choosing a minimum number of 30 occurrences, 38 keywords were analyzed in the present research. Following groupings of words that appeared written in different forms but referred to the same concept, the results of this analysis show that the word "performance" was found as a keyword in 637 documents $(42.02 \%$ of the total articles analyzed) and the word "decision making process" in 291 articles (19.20\%). As for the keyword map, the 38 concepts were grouped into 4 clusters. Moreover, the results show that the strongest cooccurrence link between keywords is formed between the concepts of "performance" and the accumulation of the two variants of the word "decision making" and "decision-making". Regarding the connection of those two concepts analyzed with other concepts, it can be observed that they create strong links with the following words: "performance" - "model", "performance" - "innovation", "decision-making" - "model", "decision-making""management".

This study can be useful to researchers and practitioners interested in studying the relationship between decision making process and performance concepts. Moreover, this research presents the current situation of the researches carried out on the investigated subject and highlights new possibilities to continue the researches on this subject, starting from a bibliometric analysis of the scientific literature in the field.

Regarding the limitations of the research, it should be noted that this analysis focused only on the information provided by a single database, Web of Science, with the possibility of excluding important papers related to the analyzed subject. Another limitation of the research was determined by the use of VOSviewer software that does not allow the pooling of information extracted from different databases to perform keyword analysis.

\section{ACKNOWLEDGEMENTS}

This study was conducted through the doctoral program, Management field, coordinator The Bucharest University of Economic Studies. This work was cofinanced from the European Social Fund through Operational Programme Human Capital 2014-2020, project number POCU/380/6/13/125015 "Development of entrepreneurial skills for doctoral students and postdoctoral researchers in the field of economic sciences".

\section{REFERENCES}

Andrés, A. (2009). Measuring Academic Research: How to Undertake a Bibliometric Study. Oxford: Chandos Publishing.

Bagstad, K.J., Semmens, D.J., Waage, S., et al. (2013). A comparative assessment of decision-support tools for ecosystem services quantification and valuation. Ecosysem Services, 5, E27-E39. doi: 10.1016/j.ecoser.2013.07.004.

Bechara, A. (2004). The role of emotion in decision-making: Evidence from neurological patients with orbitofrontal damage. Brain and Cognition, 55(1), 30-40. doi:10.1016/j.bandc.2003.04.001. 
Blanco-Mesa, F., Merigó, J.M., \& Gil-Lafuente, A.M. (2017). Fuzzy decision making: A bibliometric-based review. Journal of Intelligent \& Fuzzy Systems, 32(3), 2033-2050. doi:10.3233/JIFS-161640.

Carpenter, M.A. \& Westphal, J.D. (2001). The strategic context of external network ties: Examining the impact of director appointments on board involvement in strategic decision making. Academy of Management Journal, 44(4), 639-660. doi:10.2307/3069408.

Certo, S.T. (2003). Influencing initial public offering investors with prestige: Signaling with board structures. Academy of Management Review, 28(3), 432-446.

Cicea, C., Marinescu, C., Albu, C.F. \& Bălan, D.P. (2019). Applying Bibliometric Mapping and Clustering on Research Regarding Biomass related Innovation. Proceedings of the 33rd International Business Information Management Association Conference (IBIMA). Granada, Spain, 2404-2419.

Dabic, M., González-Loureiro, M. And Harvey, M. (2014). Evolving research on expatriates: what is 'known' after four decades (1970-2012). The International Journal of Human Resource Management, 26(3), 316-337. doi: 10.1080/09585192.2013.845238.

Handfield, R., Walton, S.V., Sroufe, R., et al. (2002). Applying environmental criteria to supplier assessment: A study in the application of the Analytical Hierarchy Process. European Journal of Operational Research, 141(1), 70-87. doi:10.1016/S03772217(01)00261-2.

Lyon, D.W., Lumpkin G.T. \& Dess, G.D. (2000). Enhancing entrepreneurial orientation research: Operationalizing and measuring a key strategic decision making process. Journal of Management, 26(5), 1055-1085. doi: 10.1016/S0149-2063(00)00068-4.

Manes, F., Sahakian, B., Clark, L., et al. (2002). Decision-making processes following damage to the prefrontal cortex. Brain, 125 (3), 624-639. doi:10.1093/brain/awf049.

Marinescu, C., Cicea, C. \& Colesca, S.E. (2019). Tracking biofuels-innovation relationship through scientific and technological advances. Management Research and Practice, 11(2), 31-44.

Moed, H.F. (2009). New developments in the use of citation analysis in research evaluation. Archivum Immunologiae et Therapiae Experimentalis, 57, 13-18. doi:10.1007/s00005009-0001-5.

Reid, S.E. \& De Brentani, U. (2004). The fuzzy front end of new product development for discontinuous innovations: A theoretical model. Journal of Product Innovation Management, 21(3), 170-184. doi:10.1111/j.0737-6782.2004.00068.x.

Van Eck, N.J., \& Waltman, L. (2011). 'Text mining and visualization using VOSviewer'. ISSI Newsletter, 7(3), 50-54.

Van Eck, N.J., \& Waltman, L. (2019). VOSviewer software version 1.6.11, developed at Leiden University's Centre for Science and Technology Studies (CWTS). Available at https://www.vosviewer.com/.

Van Eck, N.J. \& Waltman, L. (2010). Software survey: VOSviewer, a computer program for bibliometric mapping. Scientometrics, 84, 523-538. doi:10.1007/s11192-009-0146-3.

Van Eck, N. J., \& Waltman, L. (2007). VOS: A new method for visualizing similarities between objects. In H.-J. Lenz \& R. Decker (Eds.), Advances in data analysis: 
Proceedings of the 30th annual conference of the German Classification Society (pp. 299-306). Heidelberg: Springer.

Xiao, B. \& Benbasat, I. (2007). E-commerce product recommendation agents: Use, characteristics, and impact. Mis Quarterly, 31(1), 137-209.

Waltman, L., Van Eck, N.J., \& Noyons, E.C.M. (2010). A unified approach to mapping and clustering of bibliometric networks. Journal of Informetrics, 4(4), 629-635. doi:10.1016/j.joi.2010.07.002.

Webb, S.A. (2001). Some considerations on the validity of evidence-based practice in social work. British Journal of Social Work, 31(1), 57-79. doi:10.1093/bjsw/31.1.57.

WoS (2019a). 1516 selected documents - Analyze Results. Retrieved October 23, 2019, from www.webofscience.com.

WoS (2019b). 1516 selected documents - Create Citation Report. Retrieved October 23, 2019, from www.webofscience.com. 